\title{
The Researches on Exchange Rate Risk of Chinese Commercial Banks Based on Copula-Garch Model
}

\author{
Baoqian Wang, Tingting Cao, Shu Wang \\ Business School, Hohai University, Nanjing, China \\ Email: caotingtingtina@163.com
}

Received 7 March 2014; revised 6 April 2014; accepted 16 April 2014

Copyright (C) 2014 by authors and Scientific Research Publishing Inc.

This work is licensed under the Creative Commons Attribution International License (CC BY). http://creativecommons.org/licenses/by/4.0/

(c) $\underset{\mathrm{EY}}{0}$ Open Access

\begin{abstract}
After the exchange rate reforms in 2005, China has transformed the fixed exchange rate system into a floating exchange rate system dominated by market supply and demand. Commercial banks will face with greater exchange rate risk. Therefore, how to estimate exchange rate risk and keep the optimal portfolio of foreign exchange is an important research subject. This article chooses the date of the RMB exchange rate against the dollar and the yen from the January 1, 2008 to May 21, 2012 as samples, describes the joint distribution of the two assets using Copula-Garch model, thus eventually works out the optimal holding ratio of the two foreign currency assets under minimal risk situations.
\end{abstract}

Keywords

Exchange Rate Risk, Copula Function, VaR

\section{Introduction}

With the establishment of the floating exchange rate system in China, the number of foreign assets held by commercial banks is increasing, as well as frequent financial crises in the international market, exchange rate risk has become an important source of financial risk of commercial banks.

Many domestic and foreign scholars have done the analysis of exchange rate risk, Galai Dan and Michel Crouhy believe that the reason for the existence of the exchange rate risk is foreign currency exposure, which cannot be eliminated through the financial derivatives. Huali Huang thinks that the value of the foreign exchange positions held by commercial banks as the foreign exchange market exchange rate volatility is the direct cause of commercial bank exchange rate risk, and changes in the exchange rate are mainly influenced by the 
foreign exchange market supply and demand [1]. According to the comprehensive research of scholars both at home and abroad, the author thinks that the fundamental cause of the exchange rate changes is the change of market supply and demand of foreign exchange, while changes of the relationship between supply and demand in the foreign exchange market are determined by each country's domestic political and economic factors. The specific reasons are as follows: first, in economic transactions, there exists a foreign exchange exposure in the gap between financial assets and financial liabilities. Second, foreign exchange rate risks arise from international currency trading behavior of economic subject in the market. Third, the exchange rate risk and time factors are closely linked. From the intention of a deal to the end of the last transaction settlement, there are certain time intervals. Finally, exchange rate risk is derived from the multinational investment behavior of economic agents. Because of commercial banks for transnational investment, exchange rate changes will cause the bank value change, affect the company's cash flow, as well as impact on the profitability of banks [2]-[4].

The key of prevention and control of the exchange rate risk is the effective measure of exchange rate risk. The VaR method is widely used at present. In the 90's, foreign scholars began to research the VaR method, their research mainly includes the selection of VaR model, the scope of application of VaR, and the re-innovation of VaR model. In the measurement of VaR, assuming that yields obey a certain distribution is one of the earliest calculation methods of VaR parameter. But later it was found that most of the time series of financial assets showed a fat tail nature, not simply showing a normal distribution, and often extreme cases occur together, so the assumption is inconsistent with the earlier objective reality. Until 1982, Engle proposed autoregressive conditional heteroskedasticity model, referred to as the ARCH model, the model believes that the variance and conditional variances are not the same; the conditional variances are related to the error function before; this model can effectively solve the spike thick tail of financial assets time sequence model; this feature provides a new way to solve the heteroscedasticity. Robert F. Engle (1982) introduced the hypothesis and principle of each method that VaR based on, in the end, he used the monte carlo simulation method to calculate the end result based on different VaR method, and compared the result of the calculation. By comparison, the conclusion is as follows: for the present fat-tailed data, CVaR model is the best. Eric Bouye systematically introduces the application of copulas connect function in the financial sector, in addition to the common application of portfolio risk correlation, will also extends to value at risk (VaR) calculations, using copulas connect function further to analyze the credit risk and market risk [5]. Romnano using copulas connect function to calculate risk portfolio risk, he thinks that risks can be divided into individual risk and its structure risk associated with individual external structure though copulas connect function, the article also uses multivariate extremum function through monte carlo simulation to calculate market risk. Rosenberg and Schuermann used the VaR method to measure risk, and they compared the accuracy of several models to calculate the VaR values. The results showed that copula model was the best way of VaR calculation [6].

Min Chen, a domestic scholar, used the main calculation method of VaR model. She contrasts the pros and cons of various models by later accuracy test. The main calculation method she used includes the historical simulation method, the delta-normal method, etc. The adopted model includes the ARCH model and GARCH model. The final conclusion is that GARCH $(1,1)$ model based on the $t$ distribution has a better fitting effect in commercial bank exchange rate risk accuracy measurement. Qing Ye uses semi-parametric model based on GARCH model, which is a good measure of risk in China's mainland stock market fluctuation, and the semiparametric model based on GARCH model in the measurement of China's stock market risk is more accurate by comparing the different models. Lujie Sun and Manying Bo combined copula function and the VaR method, and compared the traditional VaR model and the new model. Through the empirical study of the euro and the dollar portfolio, results showed that the VaR model based on copula function can more accurately measure the risk of exchange rate [7] [8].

\section{Exchange Rate Risk Measurement Model Selection and Testing Steps}

Risk value method is the internationally accepted measure method of foreign exchange rate risk. In a certain period, determine a good confidence level in advance, the commercial bank asset portfolio value at risk showed the positions of the maximum possible losses. Holding period, the confidence level and risk factors is three factors the method must consider. The managers of commercial banks based on their risk tolerance, choose suitable holding period and the confidence level, and take factors that affect the risk of exchange rate volatility into the appropriate model, then get a possible maximum loss amount, which is the value at risk in the future. 
VaR method does not apply in financial markets when extreme abnormal fluctuations occurs such as political, military, culture, and some the long-term factors. The VaR approach as a short-term analysis tool is appropriate when financial market are stable.

VaR English full name is the Value at Risk is often translated as "Value at Risk". The statistical formula can be defined as:

$$
\operatorname{Prob}(\Delta P<\mathrm{VaR})=1-\alpha
$$

In Equation (1), "Prob” represents probability level, “ $\Delta P$ ” represents actual loss of foreign exchange assets, "VaR" represents the maximum loss of financial institutions in the foreign exchange, confidence level. $1-\alpha$ represents there's a $1-\alpha$ percent chance that the actual losses on foreign exchange assets is lower than the maximum loss. Normally, rule out other abnormal condition, the influence of a financial asset or portfolio, given a certain holding period in advance and the confidence interval of the condition, the calculation of VaR value are the biggest losses of the portfolio likely to happen. In other words, if the event is under the condition of the probability of $1-\alpha$, held at a given period, the biggest loss suffered by a financial asset or portfolio may be is not greater than calculated value of the VaR. VaR model is based on related assumptions, we should first inspect the premise before using the $\mathrm{VaR}$ model of $\mathrm{VaR}$ and test steps are as follows:

1) Must make sure the time series of financial assets is a random walk, which is the guarantee of the efficient operation of VaR calculation principle, or premise of VaR will not exist. The test for a random walk of the main financial assets time series methods including autocorrelation test, single root ADF test.

2) Test whether the inspection time sequence distribution of financial assets is normal distribution. Usually time series of financial assets distribution show rush fat-tailed, mostly distribution does not conform to the normal distribution assumption, in this case, people usually use GARCH model revise, in order to improve the accuracy of tail fitting and effect.

3) The copulas connect joint distribution test. Copulas connect function to connect the marginal distribution of financial assets of a multidimensional joint distribution of a variable joint cumulative distribution function with variable edge connects the cumulative distribution function function, describe the relationship between marginal distribution of financial assets [9].

4) Calculate the maximum loss of financial assets VaR. On the basis of financial assets distribution GARCH model and copulas connect joint distribution function. We also need to test the model fitting degree, usually uses K-S inspection. Due to model integration is difficult, we usually adopt the monte carlo simulation method to calculate the final VaR value at risk. In this paper, matlab software simulate 10,000 times and 10,000 groups of yield can be calculated, and then put different proportion of foreign exchange assets in to calculate the risk value. Finally according to the size of the risk value, select the best holding ratio proportion of foreign exchange assets.

\section{Empirical Analysis on Calculation of Exchange Rate Risk in Commercial Banks}

This article selects a total of 1088 days of historical rates of the yuan against the dollar and the yen on January 1 , 2008 to May 21, 2012 to produce 1087 samples, yields data from sina (http://finance.sina.com.cn). Because it is the yield in study, it can be done by the difference of the RMB exchange rate price. In order to make data processing more convenient, logarithm processing method is adopted in this paper, the RMB exchange rate data, obtain logarithmic yield.

$$
R_{t}=\ln P_{t}-\ln P_{t-1}
$$

In this formula:

$P_{t}$-RMB exchange rate.

$R_{t}$-yield.

Taking the logarithm of the exchange rate does not change the nature of and the relationship between the data, and the data is easy to eliminate the heteroskedasticity problem.

\subsection{Randomness Test of Model Assumptions}

\subsubsection{The Correlation Test}

First of all, we must test the yuan against the dollar and the yen exchange rate changes can accord with random 
walk. We can use the autocorrelation test for analysis. We use a sample of 300 last year do the autocorrelation test, and use the benchmark price as the sample value. Through the calculation of Eviews 6.0 software, we can draw the following results:

Above two Figure 1, Figure 2, respectively is the yuan and the yen against the dollar of auto-correlation and partial correlation, as can be seen from the table, auto-correlation and partial correlation coefficients of the dollar and the yen were in the dotted line range, There's a 95 percent chance that yield sequences of the two currencies are not related. Also observe the Q-stat is not significant, $P$ value is bigger also, also confirms this point. So, the mean equation can be estimated as:

$$
R_{t}=C+\varepsilon_{t}
$$

\subsubsection{Unit Root Test}

From Table 1 and Table 2 test results, the yuan against the dollar and the yen the ADF test result is 31.63001 and 25.67502 respectively, far less than the set threshold under three significance level, so that the sequence of yield of the yuan against the dollar and the yen is smooth.

\subsubsection{The Test of Normality}

In the use of VaR model to measure exchange rate risk of the renminbi against the dollar and the yen, also must be prior to test if series is subject to the normal distribution. If the rate of return follows a normal distribution, it can simplify the calculation method, can directly use the delta-normal method to calculate VaR, if it do not obey the normal distribution you will need to use other methods. This paper mainly uses the normal Q-Q map and J-B test to test if the samples obey normal distribution.

1) Normal Q-Q Test

It can be seen from the Figure 3 and Figure 4, the logarithmic return series of QQ figure deviates from the red line in central, and there are a lot of scattered points is fore and aft the outside the red line, which shows that

Correlogram of USD300

\begin{tabular}{|c|c|c|c|c|c|c|}
\hline \multicolumn{7}{|c|}{ Correlogram of USD300 } \\
\hline $\begin{array}{l}\text { Date: } 05 / 27 / 12 \\
\text { Sample: } 1300 \\
\text { Included observation }\end{array}$ & $16: 16$ & & & & & \\
\hline Autocorrelation & Partial Correlation & & $\mathrm{AC}$ & PAC & Q-Stat & Prob \\
\hline $1 \mid 1$ & 111 & 1 & -0.024 & -0.024 & 0.1675 & 0.682 \\
\hline ין י & יוp' & 2 & 0.066 & 0.065 & 1.4789 & 0.477 \\
\hline יו 1י & יוpי & 3 & 0.032 & 0.035 & 1.7939 & 0.616 \\
\hline \begin{tabular}{l|l}
1 & 1
\end{tabular} & \begin{tabular}{l|l}
1 & 1
\end{tabular} & 4 & -0.003 & -0.006 & 1.7976 & 0.773 \\
\hline ין ו י & ין י ו 1 & 5 & 0.080 & 0.076 & 3.7602 & 0.584 \\
\hline C. & C. 1 & 6 & -0.111 & -0.109 & 7.5834 & 0.270 \\
\hline
\end{tabular}

Figure 1. The inspection of yuan-dollar exchange rate of 300 samples.

Correlogram of JYP300

Date: 05/30/12 Time: $13: 53$

Sample: 1300

Included observations: 300

\begin{tabular}{c|c|rrrrr}
\hline \hline Autocorrelation & Partial Correlation & & AC & PAC & Q-Stat & Prob \\
\hline \hline & 1 & 1 & -0.033 & -0.033 & 0.3236 & 0.569 \\
1 & 1 & 2 & 0.032 & 0.031 & 0.6265 & 0.731 \\
1 & 1 & 3 & 0.055 & 0.057 & 1.5356 & 0.674 \\
1 & 1 & 4 & 0.025 & 0.028 & 1.7330 & 0.785 \\
1 & 1 & 5 & 0.097 & 0.096 & 4.6305 & 0.463 \\
1 & 1 & 6 & -0.020 & -0.018 & 4.7515 & 0.576 \\
\hline \hline
\end{tabular}

Figure 2. The inspection of yuan-yen exchange rate of 300 samples. 
Table 1. ADF test of dollar.

\begin{tabular}{cccc}
\hline & t-statistic & Prob. $^{*}$ \\
\hline Augmented Dickey-Fuller test statistic & -31.63001 & 0.0000 \\
\hline Test critical values: & $1 \%$ level & -3.436154 & \\
& $5 \%$ level & -2.863991 & \\
& $10 \%$ level & -2.568126 & \\
\hline
\end{tabular}

Table 2. ADF test of yen.

\begin{tabular}{cccc}
\hline & t-statistic & Prob. $^{*}$ \\
\hline Augmented Dickey-Fuller test statistic & -25.67502 & 0.0000 \\
\hline Test critical values: & $1 \%$ level & -3.436160 & \\
& $5 \%$ level & -2.863994 & \\
& $10 \%$ level & -2.568128 & \\
& & & \\
& & & \\
& & & \\
\end{tabular}

the logarithm yield of \$ sequence does not obey the normal distribution assumption. Compared to the dollar, the yen logarithm yield sequence of QQ central figure is good, but at the same time at both ends is still have a lot of scatter distribution outside the normal line, the bottom deviation to the left and top right deviation, has the characteristics of rush fat-tailed distribution. Can be seen from the QQ figure, the yuan against the dollar and yen yield sequence does not obey normal distribution.

2) J-B Inspection

From Figure 5 and Figure 6, it can be seen that in terms of skewness, skewness of logarithmic yield distribution of the yuan against the dollar is about -0.62 , against the yen is about 0.24 , the skewness of normal distribution is 0 , so on the deviation degree, the sequence of yield of the two kinds of foreign exchange do not conform to the requirements of the normal distribution. In terms of kurtosis, the yuan against the dollar is about 5.83, against the yen is 7.02, and the kurtosis of the normal distribution is 3 , so they are not conform to the requirements of normal distribution on the kurtosis. Skewness of dollar $\mathrm{S}<0$, the dollar show depreciated trend; skewness of yen $S>0$, indicating that the yen appreciation trend. Compared with QQ, J-B test pattern can see the visual characteristics of return series peak thick tail. The test shows that logarithm yield sequence of the dollar and the yen is not strictly obey the normal distribution [10].

Through the analysis of two methods of inspection above we can believe the logarithm yield of the yuan against the dollar and yen spike thick tail characteristics exist, does not obey normal distribution, thus need to use GARCH model to estimate value at risk.

\subsection{ARCH Effect Test of Yield Distribution}

1) Residual Analysis of the Dollar and the Yen

Observe the average equation residual figure dollar and yen, we can see obvious volatility clustering phenomenon. Can see yield sequence show heteroscedasticity (Figure 7, Figure 8).

2) The LM Test

First, conduct average equation LM test, taking the lag order 7, LM value is 18.79 , the $P$ value is 0.008 , there are different variance. LM test on yen average equation, taking lag order 3 , LM value is 10.37 , the $P$ value is 0.0157, there is heteroscedastic [11] (Table 3, Table 4).

3) $\operatorname{GARCH}(p, q)$ Model Estimation

$p$ and $q$ of GARCH $(p, q)$ model are selected mainly based on AIC, ARCH and GARCH. The general case of $P$ and $Q$ values are selected in the 1 or 2 , the paper calculated several scenarios by statistical software, finally choose GARCH $(1,1)$ model to describe marginal distribution. Through the Eviews 6.0 estimate results. 


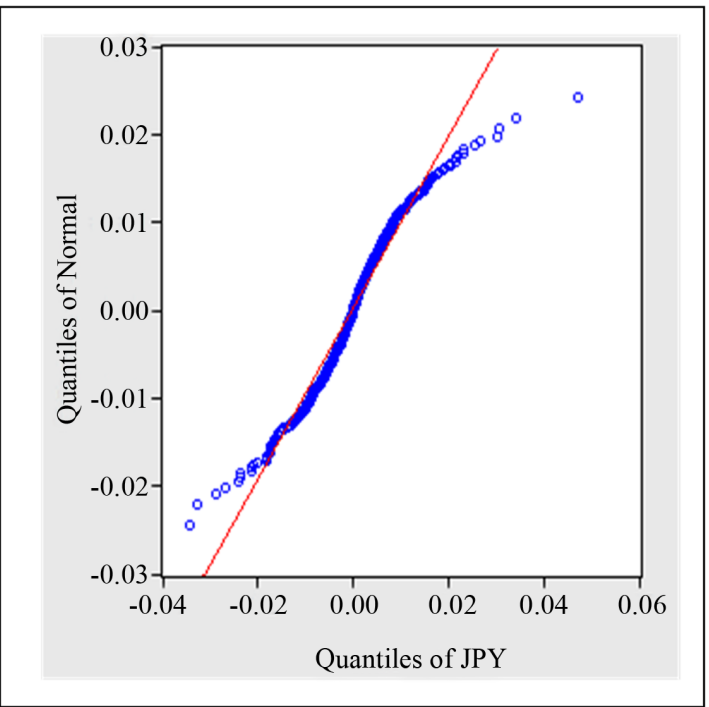

Figure 3. Normal QQ figure (dollar).

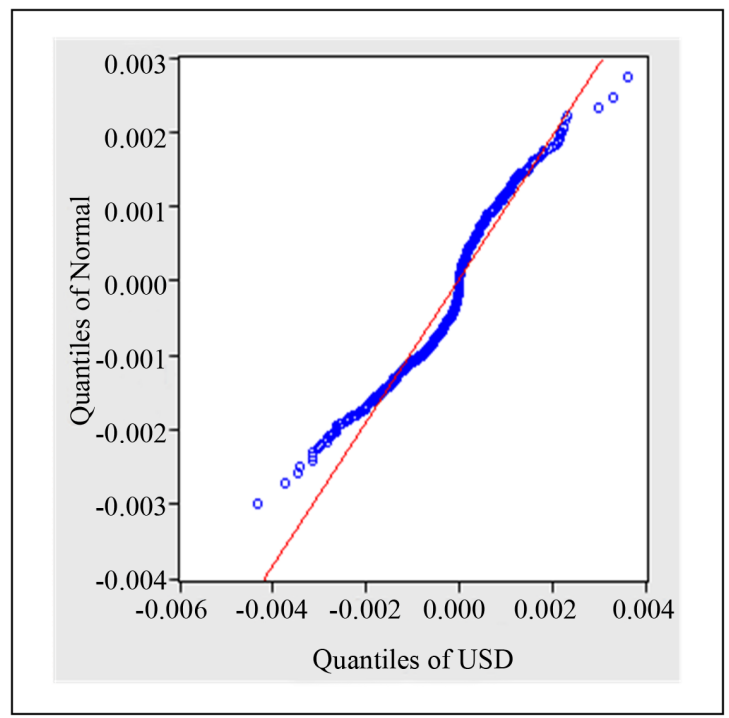

Figure 4. Normal QQ figure (yen).

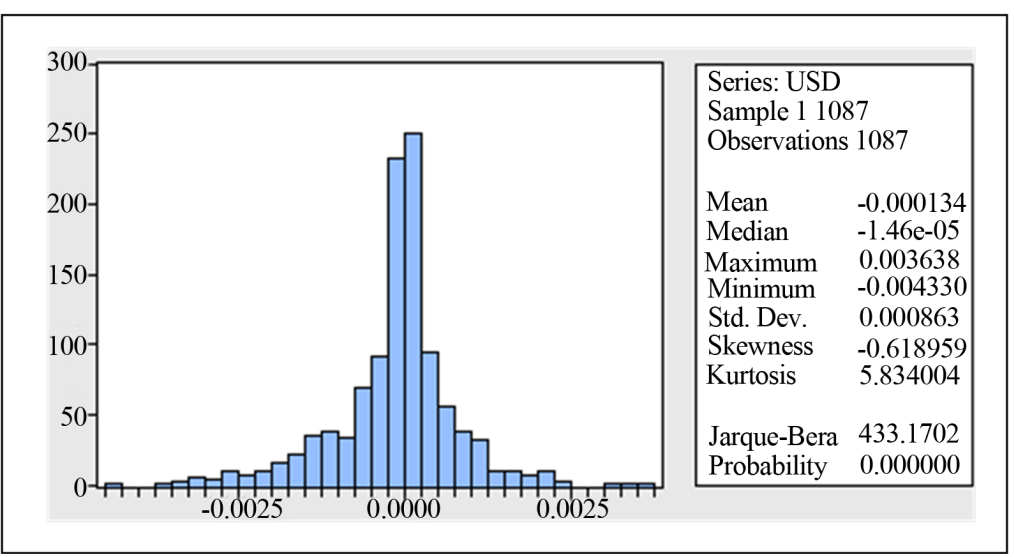

Figure 5. J-B inspection of dollar. 


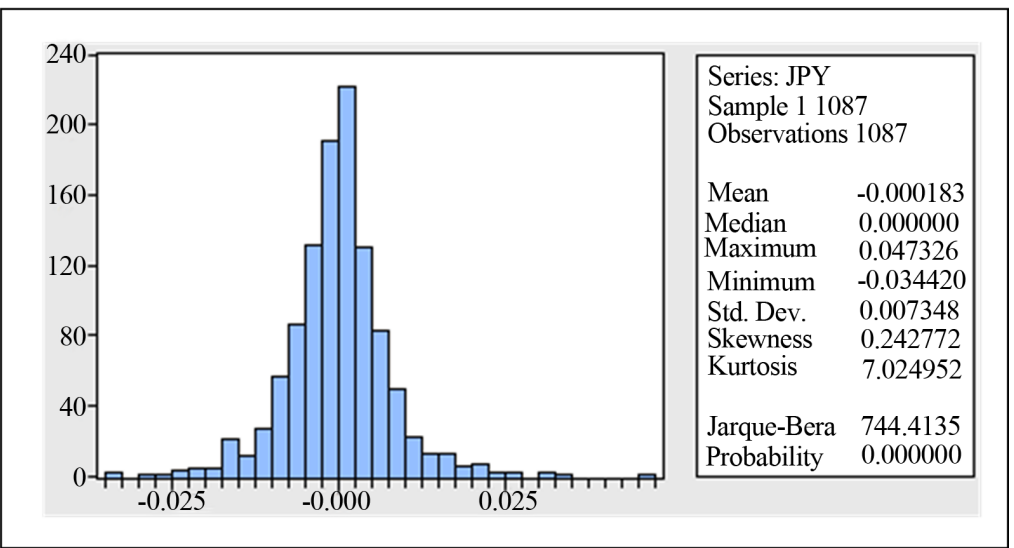

Figure 6. J-B inspection of yen.

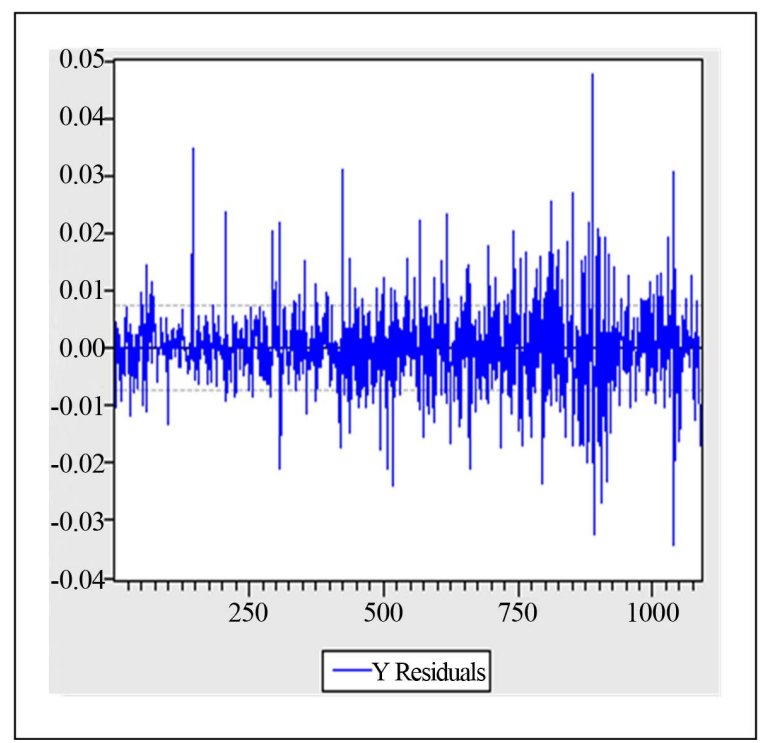

Figure 7. Average equation residual figure of dollar.

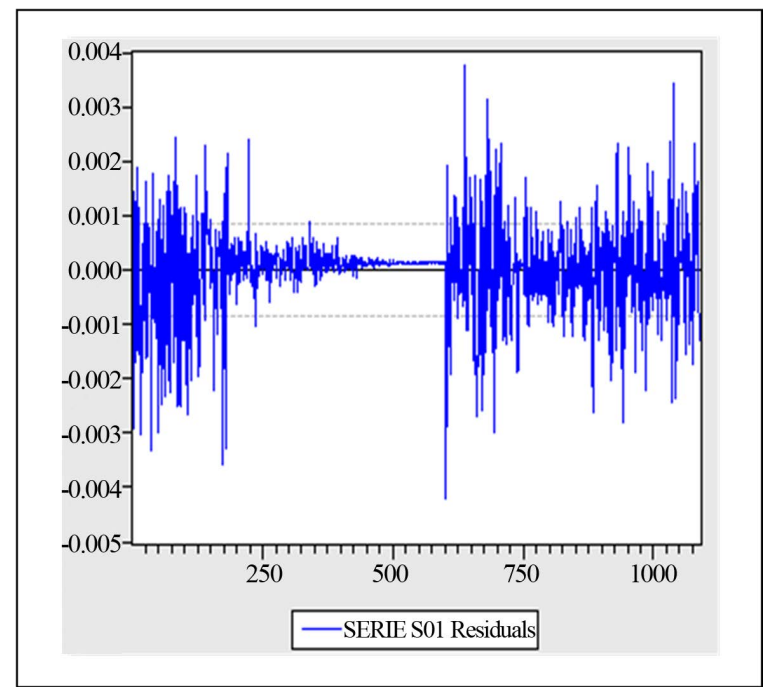

Figure 8. Average equation residual figure of yen. 
Table 3. LM test of dollar.

\begin{tabular}{cccc}
\hline \multicolumn{4}{c}{ Breusch-Godfrey serial correlation LM test: } \\
\hline F-statistic & 2.712813 & Prob. F(7, 1079) & 0.0086 \\
Obs*R-squared & 18.79963 & Prob. Chi-square (7) & 0.0088 \\
\hline
\end{tabular}

Table 4. LM test of yen.

\begin{tabular}{cccc}
\hline \multicolumn{4}{c}{ Breusch-Godfrey serial correlation LM test: } \\
\hline F-statistic & 3.476587 & Prob. F(3, 1083) & 0.0156 \\
Obs*R-squared & 10.36843 & Prob. Chi-square (3) & 0.0157 \\
\hline
\end{tabular}

As shown in Table 5, the most ARCH and GARCH coefficient is significant at the $5 \%$ significance level and it shows that GARCH $(1,1)$ model can portray the marginal distribution of Logarithmic return sequence of the RMB against the dollar and the yen.

And the AIC value based on the t-distribution of the dollar and the yen return series is less than that based on the normal distribution, showing that compared to the normal distribution, GARCH $(1,1)$ model based on the t-distribution is better. The reason is the dollar/yuan and yen/yuan yields have fat-tailed distribution.

Thus, we can draw the following four equations.

$$
\begin{aligned}
& \text { USD mean equation: } R_{1 t}=-4.20 E-07+\varepsilon_{1 t} \\
& \text { USD variance equation: } \delta_{1 t}^{2}=1.10 E-11+0.095459 \varepsilon_{1 t-1}^{2}+0.902877 \delta_{1 t-1}^{2} \\
& \text { Yen mean equation: } R_{2 t}=-0.00015+\varepsilon_{2 t} \\
& \text { Yen mean equation: } \delta_{2 t}^{2}=4.52 E-07+0.068523 \varepsilon_{2 t-1}^{2}+0.931725 \delta_{2 t-1}^{2}
\end{aligned}
$$

GARCH $(1,1)$ model is commonly used in describing the marginal distribution of time series of financial assets. It has three main parameters: ARCH coefficient, GARCH coefficient and the constant term. The value of different coefficients has different meanings. The larger GARCH coefficient shows the longer fluctuation time, the ARCH coefficient reflects volatility of time series sensitivity to market variation and the constant term reflects the time span of time series of financial assets, the greater the constant term generally shows the longer the time span. The GARCH coefficients of dollar and yen are 0.902877 and 0.931725 , which values are bigger, showing that fluctuation time of yield series of the yuan against the dollar and the yen is longer. The return coefficient of dollar and yen are 0.095459 and 0.068523 , which values are smaller, showing that the fluctuations of exchange rate yield of the yuan against the dollar and the yen is not sensitive to the changes of market conditions. The constant terms are $-4.20 \mathrm{E}-07$ and -0.00015 , which values are very small, showing that market hasn't been unusual for a long time [12].

4) Residual Test

Estimated the correlation coefficient of the GARCH $(1,1)$ model, we can use it to depict the marginal distribution of the time series of two foreign exchange assets in theory. To ensure accuracy, we also need to verify whether the chosen model can effectively describe the alienation variance phenomenon of the above-mentioned residuals. Firstly, on the basis of the model estimation, we used Eviews 6.0 software to do correlation test about residual sequence, lag intervals for endogenous was 36 and found that autocorrelation coefficient of the residual sequence of all previous 36 orders of model was not significant as a whole at the $5 \%$ significance level; secondly, we did LM test of heteroscedasticity benefits for residual and the results were as follows:

As shown from Table 6 and Table 7: in the case that lag intervals for endogenous was 2, dollar residual LM test was 0.001904 and $P$ value was 0.9990 ; yen residual LM test was $0.059823, P$ value was 0.9705 . From the results, we conclude that there is no autocorrelation in residual sequence after estimated by GARCH $(1,1)$ model. Thus, GARCH $(1,1)$ model can well depict conditional heteroscedasticity phenomenon of logarithmic yield series of RMB exchange rate.

5) K-S Test 
Table 5. Dollar/RMB and yen/RMB yield sequence of marginal distribution estimation results.

\begin{tabular}{cccccc}
\hline & $\mathrm{C}$ & $\alpha$ & $\beta$ & $\delta$ & AIC \\
\hline$R_{1}$ & Normal & $-4.62 \mathrm{E}-05$ & $8.45 \mathrm{E}-09^{*}$ & $0.091073^{*}$ & $0.897824^{*}$ \\
& $(2.40 \mathrm{E}-05)$ & $(1.03 \mathrm{E}-09)$ & $(0.013889)$ & $(0.011906)$ & -11.7703 \\
$\mathrm{~T}$ & $-4.20 \mathrm{E}-07$ & $1.10 \mathrm{E}-11$ & $0.095459^{*}$ & $0.902877^{*}$ & \\
& $(2.14 \mathrm{E}-06)$ & $(1.37 \mathrm{E}-11)$ & $(0.013466)$ & $(0.010318)$ & -12.4955 \\
$R_{2}$ & Normal & $5.87 \mathrm{E}-05$ & $2.40 \mathrm{E}-06^{*}$ & $0.077723^{*}$ & $0.877605^{*}$ \\
& $(0.000197)$ & $(4.22 \mathrm{E}-07)$ & $(0.013251)$ & $(0.019093)$ & -7.11622 \\
& -0.00015 & $4.52 \mathrm{E}-07$ & $0.068523^{*}$ & $0.931725^{*}$ & \\
\hline & $(0.000165)$ & $(3.05 \mathrm{E}-07)$ & $(0.0167)$ & $(0.016045)$ & -7.239061 \\
\hline
\end{tabular}

Note: the value of the corresponding standard deviation in parentheses; ${ }^{*}$ Show significant under $5 \%$ level of significance.

Table 6. Dollar residual LM test.

\begin{tabular}{clcc}
\hline \multicolumn{4}{l}{ Heteroskedasticity test: ARCH } \\
\hline F-statistic & 0.000949 & Prob. F(2, 1082) & 0.9991 \\
Obs*R-squared & 0.001904 & Prob. Chi-square (2) & 0.9990 \\
\hline
\end{tabular}

Table 7. Yen residual LM test.

\begin{tabular}{cccc}
\hline & \multicolumn{4}{c}{ Heteroskedasticity test: ARCH } & \\
\hline F-statistic & 0.029831 & Prob. F(2, 1082) & 0.9706 \\
Obs*R-squared & 0.059823 & Prob. Chi-square (2) & 0.9705
\end{tabular}

The first step of the empirical phase is using GARCH $(1,1)$ to depict the marginal distribution of foreign currency assets yield series and which results directly impact the following joint distribution as well as the accuracy of the final settlement results. So, before constructing joint distribution we also need to test fitting degree of the model the marginal distribution.

In this paper, K-S test was used to detect the fitting degree of GARCH $(1,1)$. Firstly, integral transform was applied to marginal distribution depicted GARCH $(1,1)$ model. Secondly, check whether the distribution after integral transform follows $(0,1)$ distribution. If it follows, we can conclude the model has good fitting effect; otherwise, we would improve the model again until model passed by K-S Test. In this paper, integral transform was applied to foreign currency assets yield series of the yuan against the dollar and the yen. We detected that correlation of those two foreign currency asset yields after transformation sequence does not exist at the chance of 95\%. The results are shown in Table 8 [13].

As shown from the K-S test, both dollars and yen $P$ values are greater than 0.05 under the $5 \%$ significance level, so the sequence after integral transform follows $(0,1)$ distribution. Thus, GARCH $(1,1)$ can be used to describe marginal distribution of the yield time series of the yuan against the dollar and the yen. After K-S test, we can choose Copula function to depict correlativity of time series and construct the joint distribution of financial assets.

\subsection{Calculated VaR Value by the Montecarlo Simulation}

As yields integral joint distribution model of dollar and yen is complicated, so using the monte carlo simulation 
method calculate VaR values and get proportion of holders of financial assets when VaR minimum. Steps are as follows:

1) Conduct Cholesky decomposition $\Sigma=A^{\prime} A$.

2) Produce two independent identically distributed random variables $Z=\left(Z_{1}, Z_{2}\right)^{\prime} \quad Z_{i} \sim N(0,1)$.

3) Let $Y=A Z$, get a $n \times L$ dimensional vector $Y$ by multiplication of $A$ and $Z$, because it is the product of $A$ and $Z, Y$ vector has both $A$ and $Z$ characteristics: the correlation coefficient matrix of each vector are $\Sigma$, and each vector are subject to $(0,1)$ the standard normal distribution.

4) Calculate $u=F\left(x_{1}\right)$ and $v=F\left(x_{2}\right)$.

5) Based on the distribution function, compute their inverse function is $r_{1}=F_{1}^{-1}(u), r_{2}=F_{2}^{-1}(v)$.

6) Conduct 10,000 times of montecarlo simulation, and calculate the 10,000 pairs of yield $\left(r_{1}, r_{2}\right)$. Consider a given portfolio investment scheme: put the money into the two assets. Let $Y=(b, 1-b)\left(r_{1}, r_{2}\right)^{\prime}$.

Find experienced value of VaR of confidence level of 0.05 according to the 10000 samples, so as to complete the risk assessment.

The simulation results are shown in Table 9 .

It is seen from Table 9, when $B$ is 0.35 , the value of $\mathrm{VaR}$ is of the minimum. So we can get the minimum risk of foreign exchange portfolio: hold $35 \%$ of the Japanese yen, $65 \%$ of the dollar.

\section{Research Conclusion}

This paper chooses the sample data of yield on foreign exchange assets of dollar and yen from January 1, 2008 to May 21, 2012, and finally comes to the results that the optimal proportion of foreign currency assets held by

Table 8. Marginal distribution of K-S test.

\begin{tabular}{|c|c|c|}
\hline & K-S value & $P$ value \\
\hline$R_{1}$ & 0.0192 & 0.1321 \\
\hline$R_{2}$ & 0.0231 & 0.2231 \\
\hline \multicolumn{3}{|c|}{$\begin{array}{l}\text { Table 9. The VaR of different combinations } \\
=0.05) \text {. }\end{array}$} \\
\hline b & & $\mathrm{VaR}$ \\
\hline 0 & & 0.00951 \\
\hline 0.1 & & 0.00950 \\
\hline 0.11 & & 000949 \\
\hline ....... & & \\
\hline 0.32 & & 0.00941 \\
\hline 0.33 & & 0.00939 \\
\hline 0.34 & & 0.00938 \\
\hline 0.35 & & 000933 \\
\hline 0.36 & & 0.00935 \\
\hline 0.37 & & 0.00939 \\
\hline ....... & & \\
\hline 1 & & 0.01131 \\
\hline
\end{tabular}


the Chinese Commercial Banks is 35\% the yen, 65\% dollars. In addition, the dollar exchange rate has a smaller fluctuation than the yen, and its basic trend also goes stronger.

\section{References}

[1] Choi, J.J., Elyasiani, E. and Kopecky, K.J. (1992) The Sensitivity of Bank Stock Returns to Market Interest and Exchange Rate Risks. Journal of Banking \& Finance, 16, 983-1004. http://dx.doi.org/10.1016/0378-4266(92)90036-Y

[2] Choi, J.J. and Elyasiani, E. (1997) Derivative Exposure and the Interest Rate and Exchange Rate Risks of U.S. Banks. Journal of Financial Services Research, 12, 267-286. http://dx.doi.org/10.1023/A:1007982921374

[3] Wetmore, J.L. and Brick, J.R. (1994) Commercial Bank Risk: Market, Interest Rate and Foreign Exchange. Journal of Financial Services Research, 17, 585-596.

[4] Rockinger, M. and Jondeau, E. (2001) Conditional Dependency of Financial Series: An Application of Copulas. Groupe HEC-Department Finance Economics and Banquede France-Economic Study and Research Division.

[5] Zhang, J. (2006) Study on Our Country Commercial Bank Exchange Rate Risk Management under the Conditions of Opening up. Master Thesis, China Journal Net.

[6] Wu, Z.X., Ye, W.Y. and Miao, B.Q. (2004) Analysis Based on Foreign Portfolio Risk. Chinese Journal of Management Science, 12, 1-5.

[7] Chen, M. (2007) An Empirical Study on the "VaR” Model in the RMB Exchange Rate Risk Measurement in China. Dissertation, Qingdao University, Qingdao.

[8] Chen, J. (2009) Under Current Exchange Rate System of China’s Commercial Bank Exchange Rate Risk Management Research. Dissertation.

[9] http://finance.sina.com.cn

[10] Bo, M.Y. and Sun, L.J. (2007) Comparison between Three Copula-VaR Method and Traditional VaR Method. Technology and Economy Research of Economy, 19, 35-41.

[11] Gao, X.Y. (2009) Consideration on the Exchange Rate Risk Management of Commercial Banks. Financial Research, 12, 48-52.

[12] Kris, P. and Li, J.L. (2005) VaR Methods: The Effective Measure and Value of Commercial Banks’ Market Risk Creation Effect Evaluation. Comparative Economic and Social Systems, 15, 52-59.

[13] Wang, G.Z. and Wang, F. (2005) Study on Application of VaR in the Risk Management of Commercial Banks in China Market. China's Circulation Economy, 19, 25-33. 